\title{
Coping with a talent flood
}

\section{Jerusalem}

WITH immigrant engineers and $\mathrm{PhDs}$ pushing brooms on the streets of Tel Aviv suburbs, the term 'sanitary engineer' has lost its tongue-in-cheek character when referring to street cleaners in Israel. The country has not yet been able to cope with the flood of immigrant scientists and engineers sweeping in from the Soviet Union.

But in the face of this case of talent overload, the Israeli government and private foundations are trying a variety of strategies to integrate all this brainpower into the country's economy. If the effort is successful, the newcomers could trigger a new era of economic growth for the country.

Since the current wave of mass immigration began in December 1989, some 350,000 Soviet Jews have arrived in Israel, including 4,500 scientists and almost 40,000 engineers. In all, one million Soviet immigrants are expected to arrive in Israel in a five-year period, increasing the country's population by some 20 per cent.

Even if the reforms in the Soviet Union cause the tide to slow, Israel will still face a major adjustment. "The burden is overwhelming," says Deborah Lipson of the Zionist Forum, a volunteer organization for Soviet immigrants. "It is the equivalent of 15 million immigrants arriving in the United States in one year.'

With the burden, however, comes an opportunity. Because Israel has few significant natural resources, its fortunes rest in large part on its scientific and technical skills, and the anticipated immigration should double the number of scientists and quadruple the number of engineers in Israel by 1995 .

Aware of the potential, the government has in the past year started to nurture 2,000 immigrant scientists and engineers through their first years in the country. Some $\$ 70$ million has been allocated to programmes aimed at providing interim employment for these newcomers until they can be absorbed by the country's expanding industrial and academic base.

Many of the immigrant scientists and most of the engineers, however, must cope on their own. For most this means temporary employment in less exalted fields some have actually become municipal street cleaners - and many face a permanent change in career.

"The problem is not so much the numbers of scientists and engineers, it's the condensed time span in which they're coming," says Baruch Eyal, a Ministry of Science official dealing with immigrant scientists. An earlier immigration wave that brought 180,000 newcomers from the Soviet Union beginning in the 1970 s saw an even higher percentage of scientists, he noted, but the flow had been spread over 15 years and appropriate jobs were found for virtually all of them. "The absorption of scientists and engineers depends on the economic growth of the country and unfortunately the growth in immigration now is much higher than the growth of the GNP," he said.

The most ambitious government programme is the creation of technological incubators around the country in which immigrant scientists and engineers work on projects with commercial potential that have been proposed by local industries or that the new citizens have proposed themselves. (By one estimate, Soviet immigrant scientists and engineers have brought with them some 100,000 patents.) Fourteen such centres are to be set up - several are already functioning - and they will provide employment for at least a year or two for some 700 immigrants, mostly PhDs. The hope is that the incubators will come up with new processes or products that will draw private capital.

In setting up the centres, the government is giving preference to fields that Israel is interested in developing, such as microelectronics, electro-optics, chemistry, software and superconductivity. The incubators are in existing universities, research institutes and industries.

Some immigrant scientists are finding jobs directly in industry. To encourage this process, the (Immigrant) Absorption Ministry pays about 85 per cent of the modest basic salary (about $\$ 800$ a month) for the first year in the hope that their employers will take them on as unsubsidized workers thereafter.

A fund administered by the Israel Academy of Sciences provides special treatment for a score of scientific superstars among the immigrants, providing them with comfortable salaries and laboratories for an extended period.

Israel's seven institutions of higher education have provided a limited number of employment opportunities for immigrant academics who have completed the obligatory six months of intensive Hebrew language courses. An expected expansion of universities - largely because of the Soviet immigration - will provide some 2,000 faculty posts over the next five years, and half are expected to go to immigrants.

Many of the immigrants have adjusted to the need for a change of career. Scores of Soviet science $\mathrm{PhDs}$ are being retrained as high school teachers, which should help improve science education in Israel. Immigrant geologists are a glut on the market and many are being retrained as surveyors. Some social scientists have registered for retraining as social workers. Marxist-trained economists will have to make radical career adjustments, but Soviet psychologists surprisingly find it easy to find work in Israel after mastering the language. "The first Soviet psychology faculty was not established until 1966 in Moscow and it was set up along Western lines," says Shmuel Adler, who heads the department dealing with scientists at the Absorption Ministry. "But we have more trouble finding acceptance for Soviettrained psychiatrists."

Israeli administrators have found the quality of the Soviet scientists and academics uneven. "In the theoretical sciences - math, physics, astrophysics they're at the top of their field," Adler says. However, many of the other scientists and engineers must learn to adjust to Western standards and Western equipment.

The placement of immigrant scientists has also become the object of a number of private and institutional efforts. The Satec Corporation was founded for this purpose by an immigrant Soviet scientist, Herman Branover, who arrived in Israel in 1972 and now teaches magnetohydrodynamics at Ben-Gurion University in Beersheba. Branover established the high-technology company in Jerusalem four years ago with funding from foreign investors. It now employs 15 Soviet immigrant scientists and engineers together with sales and administrative staff.

One of Satec's scientists is Solomon Flax, a 60-year-old hydro-metallurgist who developed a technique in the Soviet Union for removing precious metals from industrial wastes using an environment-friendly and relatively cheap bromide solution rather than the cyanide conventionally used. Although he held more than 40 patents in the Soviet Union, he had not patented this process before he was dismissed from his university research job in the Ukraine after applying for an emigration visa to Israel. For nine years, barred from research work, he supported his family by using his technique to extract precious metals from castoff objects and then selling the metal. At Satec, he has obtained a US patent on his process and is negotiating with foreign companies for a pilot project.

Government planners hope that immigration will help to increase the gross national product by 10 per cent in 1992 and that the expansion of the economy by 1993 will permit absorption of as many immigrant scientists as arrive that year. By 1994, they hope to be able to deal with the backlog of unemployed scientists. Whether or not this is a realistic estimate, the transition period will clearly be painful for many of the immigrants, as well as a major burden for the country as a whole. If all goes well, however, the Israeli economy will be well prepared for the new millennium.

Abraham Rabinovich 